\title{
Effects of ciclesonide and fluticasone on cortisol secretion in patients with persistent asthma
}

\author{
E. Derom*, R. Louis*, C. Tiesler", R. Engelstätter", J-M. Kaufman ${ }^{+}$and G.F. Joos*
}

ABSTRACT: We compared the systemic and clinical effects of ciclesonide (CIC) and fluticasone propionate (FP) administered, in addition to $\mathrm{CIC} 160 \mu \mathrm{g} \cdot$ day $^{-1}$ and salmeterol $50 \mu \mathrm{g}$ twice daily, in 32 patients with persistent asthma using a randomised double-blind, placebo-controlled, doubledummy, five-period crossover design.

All patients exhibited a provocative concentration leading to a $20 \%$ decrease in forced expiratory volume in $1 \mathrm{~s}\left(\mathrm{PC}_{20}\right)$ methacholine $<8 \mathrm{mg} \cdot \mathrm{mL}^{-1}$ and a $\mathrm{PC}_{20}$ adenosine $<60 \mathrm{mg} \cdot \mathrm{mL}^{-1}$. Primary outcome was 24-h serum cortisol suppression after 7 days. Secondary outcomes were changes in $\mathrm{PC}_{20}$ methacholine and adenosine after 9 days.

FP $500 \mu \mathrm{g} \cdot \mathrm{day}^{-1}$ and $1,000 \mu \mathrm{g} \cdot \mathrm{day}^{-1}$ significantly suppressed cortisol secretion versus placebo by $-46.2(95 \%$ confidence interval $(\mathrm{Cl})-83.8--8.5) \mathrm{nmol} \cdot \mathrm{L}^{-1}$ and by $-76.1(95 \% \mathrm{Cl}-112.9--39.3)$ $\mathrm{nmol} \cdot \mathrm{L}^{-1}$, respectively. Neither dose of CIC (320 nor $\left.640 \mu \mathrm{g} \cdot \mathrm{day}^{-1}\right)$ had a significant suppressive effect $\left(-28.2(95 \% \mathrm{Cl}-65.5-9.2) \mathrm{nmol}^{-1}\right.$ and $-37.3(95 \% \mathrm{Cl}-74.7-0.0) \mathrm{nmol} \cdot \mathrm{L}^{-1}$, respectively). Differences between FP $1,000 \mu \mathrm{g} \cdot \mathrm{day}^{-1}$ and both CIC treatments were statistically significant (CIC $320 \mu \mathrm{g} \cdot$ day $^{-1}:-48.0(95 \% \mathrm{Cl}-84.8--11.1) \mathrm{nmol}^{-\mathrm{L}^{-1}}$; CIC $640 \mu \mathrm{g} \cdot \mathrm{day}^{-1}$ : -38.8 (95\% Cl -75.7- -1.9) $\mathrm{nmol} \cdot \mathrm{L}^{-1}$ ). Compared with placebo, the increase in $\mathrm{PC}_{20}$ adenosine after the four treatments was small, but significant. Greater improvements in PC20 adenosine were seen with FP $500 \mu \mathrm{g} \cdot \mathrm{day}^{-1}$ (1.8 (95\% Cl 1.0-2.6) doubling concentrations) compared with $\mathrm{CIC} 320 \mu \mathrm{g} \cdot$ day $^{-1}$ (0.9 (95\% Cl 0.11.7) doubling concentrations). No significant difference was seen between CIC $640 \mu \mathrm{g} \cdot \mathrm{day}^{-1} \mathrm{and}^{-1}$ FP $1,000 \mu \mathrm{g} \cdot$ day $^{-1}$.

For a similar decrease in hyperresponsiveness, cortisol secretion was suppressed significantly with moderate-to-high doses of fluticasone propionate, but not with ciclesonide.

KEYWORDS: Aerosol therapy, anti-asthmatic agent, asthma, bronchial hyperreactivity, cortisol, inhaled corticosteroids

I nhaled corticosteroids (ICS) are the most effective controller medications currently available to treat asthma. They reduce airway inflammation and hyperresponsiveness, improve symptoms, pulmonary function and quality of life [1, 2], and decrease hospitalisations [3] and mortality rate [4]. Thus, ICS are the guidelinerecommended first-line treatment for all patients with persistent forms of the disease [5]. Although the vital role of ICS in the management of asthma is generally recognised and ICS are well tolerated at low-to-medium doses, it has been claimed that the long-term administration of high doses of ICS has a potential for systemic adverse events (AEs), such as growth inhibition, osteoporosis, suppression of hypothalamic-pituitary-adrenal (HPA)axis function [6], or even adrenal crisis [7]. This potential for AEs with ICS is a concern for patients and physicians, and may contribute to intentional nonadherence [8] and sub-optimal prescribing [9].

Ciclesonide (CIC) is a novel, airways-targeted ICS that is delivered as an inactive compound and converted by esterases to the active metabolite (desisobutyryl-ciclesonide) in the airways, where it elicits its anti-asthmatic effect [10-13]. Several trials have shown that doses $\leqslant 1,280 \mu \mathrm{g} \cdot$ day $^{-1}$ of CIC do not produce clinically relevant HPA-axis suppression in both healthy volunteers and asthma patients [13-18]. Fluticasone propionate (FP) is an established ICS, which, however, has been associated with pronounced suppression of HPA-axis function in healthy volunteers [19] and, to a lesser extent, in asthma patients $[14,15,20-22]$. Thus, the current study was designed to assess the safety of CIC

\section{AFFILIATIONS}

Depts of *Respiratory Medicine and +Endocrinology, Ghent University Hospital, Ghent,

\#Dept of Respiratory Diseases,

Université de Liège

Liège, Belgium.

"Nycomed Pharma

Konstanz, Germany.

CORRESPONDENCE

E. Derom

Dept of Respiratory Medicine

Ghent University Hospital

De Pintelaan 185

B-9000 Ghent

Belgium

Fax: 3293322341

E-mail: eric.derom@Ugent.be

Received:

May 282008

Accepted after revision:

January 012009

SUPPORT STATEMENT

This study was funded by Nycomed Pharma.

STATEMENT OF INTEREST

Statements of interest for E. Derom C. Tiesler, R. Engelstätter and G.F. Joos, and for the study itself can be found at www.erj.ersjournals. com/misc/statements.dtl

European Respiratory Journal Print ISSN 0903-1936 Online ISSN 1399-3003 
and FP in patients with persistent asthma chronically treated with ICS. More specifically, we wanted to address the following. 1) Whether moderate-to-high doses of inhaled CIC suppress 24-h serum and urinary cortisol levels and biochemical markers of bone formation in patients with moderate, persistent asthma and how these effects compare with those of moderate-to-high doses of FP. 2) To what extent do moderateto-high doses of $\mathrm{CIC}$ reduce airway responsiveness to adenosine and methacholine, and how these effects compare with those of moderate-to-high doses of FP. 3) Whether one of the two investigated formulations is superior in terms of the ratio between clinical effect and systemic effect.

\section{METHODS}

\section{Patients}

Male and female patients (aged 18-65 yrs) known to have persistent asthma for $>6$ months, as defined by the Global Initiative for Asthma, were allowed to participate in the study. Patients were included if their current treatment consisted of a constant dose of a moderate-to-high daily dosage of ICS alone (beclomethasone dipropionate $\leqslant 1,000 \mu \mathrm{g} \cdot$ day $^{-1}$ or equivalent) or a combination of low doses of ICS with long-acting $\beta_{2^{-}}$ agonists (LABA; beclomethasone $200 \mu \mathrm{g}$ b.i.d. or equivalent plus salmeterol $50 \mu \mathrm{g}$ b.i.d. or formoterol $\leqslant 12 \mu \mathrm{g}$ b.i.d.) for $>4$ weeks. Patients with severe persistent asthma were excluded to avoid drop-outs. Patients had to demonstrate a forced expiratory volume in $1 \mathrm{~s}$ (FEV1) of $>60 \%$ predicted at the start of the study and at randomisation. All the patients exhibited a provocative concentration leading to a $20 \%$ decrease in post-saline FEV1 (PC20) methacholine $<8 \mathrm{mg} \cdot \mathrm{mL}^{-1}$ and a PC20 adenosine $<60 \mathrm{mg} \cdot \mathrm{mL}^{-1}$. Patients were also required to have normal HPA-axis function (serum cortisol concentration at $08: 00 \mathrm{~h}( \pm 30 \mathrm{~min})>5 \mu \mathrm{g} \cdot \mathrm{dL}^{-1}$ $\left.\left(>138 \mathrm{nmol} \cdot \mathrm{L}^{-1}\right)\right)$ and not to have experienced an asthma exacerbation or respiratory tract infection within 8 weeks prior to the start of the study.

Patients were excluded if they: had used systemic steroids within 4 weeks of the start of the study or more than three times during the last 6 months; had chronic obstructive pulmonary disease and/or other pulmonary diseases; had a history of other medical conditions known to affect cortisol levels (e.g. Cushing's Syndrome); or were receiving drugs known to affect endogenous cortisol production (e.g. anabolic steroids or androgens). Females were excluded if they were pregnant, breastfeeding or not using safe contraception, were of childbearing potential (i.e. might become pregnant) or were $<1$ yr post-menopausal.

This study was conducted in accordance with the rules of the International Conference on Harmonisation Good Clinical Practice and the ethical principles of the Declaration of Helsinki. Written consent was obtained from the patients before the start of the study, and the protocol was reviewed and approved by the appropriate Independent Ethics Committee (Ghent University Hospital, Ghent, Belgium or University of Liège, CHU Sart-Tilman, Liège, Belgium) or Institutional Review Boards.

\section{Study design}

This randomised, double-blind, double-dummy, placebocontrolled, five-period crossover study was conducted at two centres in Belgium (fig. 1). During a 4-6 week run-in period, patients were administered CIC $160 \mu \mathrm{g}$ in the evening plus salmeterol $50 \mu \mathrm{g}$ b.i.d. This treatment was continued throughout the entire study. CIC was chosen because previous studies have shown that daily doses of $\leqslant 1,280 \mu \mathrm{g}$ CIC had no clinically relevant effect on cortisol secretion [14, 16, 17]. Following the run-in period, patients were randomly assigned to one of 10 treatment sequences, occurring in a Latin square and its mirror, for which a computer generated randomisation list was used (table 1). These 10 sequences were uniform on the periods (each treatment was applied with the same frequency in each period) and on the subjects (each treatment was applied with the same frequency within each subject), and balanced with respect to a first-order carry-over effect (each treatment preceded every other treatment the same number of times).

Each treatment sequence consisted of five-period treatments which contained one of the following study medications (all administered via hydrofluoroalkane-metered dose inhaler), which were administered in addition to the maintenance dose of CIC $160 \mu \mathrm{g} \cdot$ day $^{-1}$. The treatment sequences were: CIC $160 \mu \mathrm{g}$ b.i.d. (ex-actuator); CIC $320 \mu \mathrm{g}$ b.i.d. (ex-actuator); FP $250 \mu \mathrm{g}$ b.i.d. (ex-valve; $220 \mu \mathrm{g}$ b.i.d. ex-actuator); FP $500 \mu \mathrm{g}$ b.i.d. (exvalve; $440 \mu \mathrm{g}$ b.i.d. ex-actuator); or placebo. Due to the code labelling, neither the investigator nor anyone at the study centre knew which drug or dosage was administered. The FP doses were based on previous observations, showing the equivalence of CIC $320 \mu \mathrm{g} \cdot \mathrm{day}^{-1}$ with FP $500 \mu \mathrm{g} \cdot \mathrm{day}^{-1}$ in terms of bronchial responsiveness to methacholine $[15,23]$. The study medication was inhaled at 08:00 $\mathrm{h}$ and 20:00 $\mathrm{h}( \pm 30 \mathrm{~min})$, starting at the evening of each period. The last inhalation took place 30-60 $\mathrm{min}$ before the methacholine provocation on the ninth day of treatment. Each treatment period was separated by a 4-12-week washout period, to allow for all previously administered study drug to be cleared from the system and to allow PC20 adenosine [14] and serum cortisol [20, 24] to return to baseline values.

\section{Spirometry and measurement of airway hyperresponsiveness}

Spirometry was performed at the start of the study (at 08:0010:00 h) and repeated at the beginning and end of each 9-day treatment period at approximately the same time-point. The highest value from three acceptable tests was recorded for FEV1. Rescue medication had to be withheld for $\geqslant 8 \mathrm{~h}$ and LABAs for $\geqslant 24 \mathrm{~h}$ prior to each lung function measurement.

Challenge tests were performed at the start of the study and at the end of each treatment period (visits T2, T5, T8, T11 and T14; fig. 1) 30-60 min after the last dose of study medication, according to a protocol that has been described elsewhere $[14,25]$. Methacholine solutions were nebulised with a Wiesbadener Doppel inhalator (Wiesbadener InhalatorenVertrieb, Wiesbaden, Germany), driven at an airflow of $6 \mathrm{~L} \cdot \mathrm{min}^{-1}$ and generating an output of $0.1 \mathrm{~mL} \cdot \mathrm{min}^{-1}$ [25]. Median mass particle size of the aerosol was $3.5 \mu \mathrm{m}$. Each patient used the same nebuliser for the whole study. The aerosol was inhaled during 2 min of quiet breathing with the outlet of the nebuliser in the mouth and the nose occluded with a clip. Three baseline readings were followed by inhalation of aerosolised saline. If the FEV1 had not fallen by $>10 \%$, 


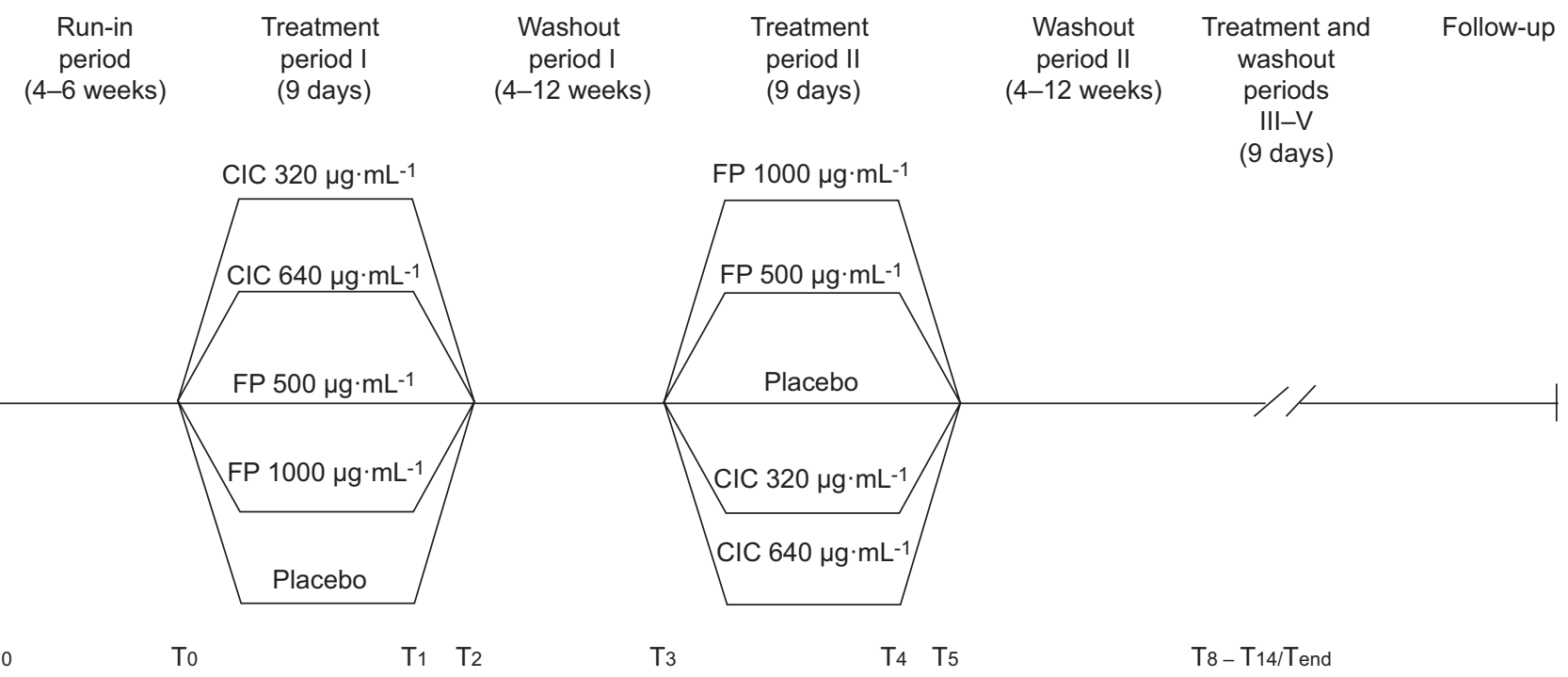

FIGURE 1. Study design. Treatment visits ( $T_{1} \mathrm{~T}_{0}-\mathrm{T}_{1}, \mathrm{~T}_{3}-\mathrm{T}_{4}, \mathrm{~T}_{6}-\mathrm{T}_{7}, \mathrm{~T}_{9}-\mathrm{T}_{10}$ and $\mathrm{T}_{12}-\mathrm{T}_{13}$ were separated by $7 \pm 0$ days. Visits $\mathrm{T}_{0}-\mathrm{T}_{2}, \mathrm{~T}_{3}-\mathrm{T}_{5}, \mathrm{~T}_{6}-\mathrm{T}_{8}, \mathrm{~T}_{9}-\mathrm{T}_{11}$ and $\mathrm{T}_{12}-\mathrm{T}_{14}$ were separated by $9(-2 /+3)$ days. CIC: ciclesonide; FP: fluticasone propionate.

aerosolised methacholine was administered with the initial concentration being $0.031 \mathrm{mg} \cdot \mathrm{mL}^{-1}$. The concentration was doubled after each step. Spirometric measurements were performed 1 and 3 min after each concentration; the lowest out of these two was retained for analysis. The time interval between each step was $5 \mathrm{~min}$. The procedure was terminated once FEV 1 had decreased by $\geqslant 20 \%$ or when the maximum methacholine concentration $\left(32 \mathrm{mg} \cdot \mathrm{mL}^{-1}\right)$ had been reached. The PC20 methacholine was calculated via linear interpolation on a logarithmic dose-response curve. If the FEV1 had not fallen by $\geqslant 20 \%$ at the maximum methacholine concentration of $32 \mathrm{mg} \cdot \mathrm{mL}^{-1}$, the value was substituted by $64 \mathrm{mg} \cdot \mathrm{mL}^{-1}$.

Following methacholine challenge, the patient was allowed to recover for 2-4 h (without use of rescue medication). If FEV1 had returned to $>90 \%$ of the pre-challenge value, an adenosine challenge was performed in the same manner as detailed above (doubling concentrations ranging $1.563-410 \mathrm{mg} \cdot \mathrm{mL}^{-1}$

\begin{tabular}{|c|c|c|c|c|c|}
\hline TABLE 1 & \multicolumn{5}{|c|}{$\begin{array}{l}\text { List of the } 10 \text { permutations of order used for the } \\
\text { five treatments }\end{array}$} \\
\hline Sequence & TI & TII & TIII & TIV & TV \\
\hline 1 & CIC 320 & CIC 640 & PLAC & FP 500 & FP 1000 \\
\hline 2 & CIC 320 & PLAC & CIC 640 & FP 1000 & FP 500 \\
\hline 3 & CIC 640 & CIC 320 & FP 500 & PLAC & FP 1000 \\
\hline 4 & CIC 640 & FP 500 & CIC 320 & FP 1000 & PLAC \\
\hline 5 & FP 500 & CIC 640 & FP 1000 & CIC 320 & PLAC \\
\hline 6 & FP 500 & FP 1000 & $\mathrm{CIC} 640$ & PLAC & CIC 320 \\
\hline 7 & FP 1000 & FP 500 & PLAC & CIC 640 & CIC 320 \\
\hline 8 & FP 1000 & PLAC & FP 500 & CIC 320 & $\mathrm{ClC} 640$ \\
\hline 9 & PLAC & CIC 320 & FP 1000 & CIC 640 & FP 500 \\
\hline 10 & PLAC & FP 1000 & CIC 320 & FP 500 & $\mathrm{CIC} 640$ \\
\hline
\end{tabular}

diluted in $0.9 \%$ saline) and PC20 was recorded. If the FEV1 had not fallen by $\geqslant 20 \%$ at the maximum adenosine concentration of $410 \mathrm{mg} \cdot \mathrm{mL}^{-1}$, that value was substituted by $820 \mathrm{mg} \cdot \mathrm{mL}^{-1}$. Patients unable to complete an adenosine challenge on the same day as the methacholine challenge returned on the following day.

\section{Cortisol assessments}

After 7 days of each treatment, 24-h hour serum profiles were obtained from all patients (visits T1, T4, T7, T10 and T13; fig. 1). At these visits, patients stayed at the study site for $24 \mathrm{~h}$ and $5 \mathrm{~mL}$ of blood was drawn at 2-h intervals starting at 20:00 h $( \pm 10 \mathrm{~min})$ until $20: 00 \mathrm{~h}( \pm 10 \mathrm{~min})$ the following day. Urine was collected over $24 \mathrm{~h}$ at the same visits. Creatinine was also measured in the samples.

\section{Bioanalytical methods}

Blood samples for cortisol analysis were collected in tubes without anticoagulant. After collection the tubes were mixed gently and incubated for a minimum of $10 \mathrm{~min}$ and a maximum of $2 \mathrm{~h}$ before centrifugation for $15 \mathrm{~min}$ at $1,600 \times g$ at room temperature. The serum was then transferred to new tubes and stored at $-20^{\circ} \mathrm{C}$ until analysis. Urine was collected for $\sim 24 \mathrm{~h}$, the total volume recorded and one teaspoon of sodiumazide per $2.5-\mathrm{L}$ container added as a preservative. Well-mixed aliquots were stored at $-20^{\circ} \mathrm{C}$. Serum and urinary cortisol were measured using the GammaCoat $\left({ }^{125} \mathrm{I}\right)$ Cortisol Radioimmunoassay Kit (Diasorin, Saluggia, Italy), which is based on the competitive binding principles of radioimmunoassay. Urine was extracted before radioimmunoassay of cortisol after addition of a titrated cortisol internal standard for recovery monitoring. The limit of quantification was $0.5 \mu \mathrm{g} \cdot \mathrm{dL}^{-1}$ with an intra-batch coefficient of variation of $3 \%$ and an inter-batch coefficient of variation between $5.5-7.1 \%$. For a given patient, all samples were assayed for cortisol within the same assay run. Possible interference of the trial medication with the cortisol assay antibody was assessed and no interference was found. Urinary creatinine was measured 
with a kinetic colorimetric assay using a Hitachi MODULAR-P analyzer (Roche, Tokyo, Japan).

\section{Assessment of bone formation makers}

Blood samples to determine serum biochemical markers of bone formation were obtained on the second day of visits ( $\mathrm{T} 1$, $\mathrm{T} 4, \mathrm{~T} 7, \mathrm{~T} 10$ and $\mathrm{T} 13)$ at 08:00 $\mathrm{h}( \pm 10 \mathrm{~min})$ after $8 \mathrm{~h}$ of fasting. All samples from a given patient were assayed in a single assay run using commercial immunoassays for bone alkaline phosphatase (ACCESS Immunoassay Systems; Beckman Coulter Inc., Galway, Ireland), serum osteocalcin (Osteometer Biotech A/S, Copenhagen, Denmark) and serum N-terminal propeptide of type 1 procollagen (P1NP; Orion Diagnostica, Espoo, Finland).

\section{Adverse events}

Safety was assessed throughout the study by neutral questioning.

\section{Statistical analysis}

The primary variable was the 24-h serum cortisol mesor, calculated by means of the area under the curve of the 24-h serum cortisol profile (AUC0-24h) divided by the respective time interval (20:00 $\mathrm{h}$ until 20:00 $\mathrm{h}$ the following day) using the trapezoidal rule. Replacement of missing values or of outliers was not performed. A second important variable was 24-h free urine cortisol adjusted for creatinine.

To address the multiplicity issue, a strategy with a priori ordered hypotheses was applied which preserves the family wise error of the procedure at $\alpha=0.025$ (one-side). Consequently, superiority hypotheses for 24-h serum cortisol mesor and 24-h free urine cortisol adjusted for creatinine were one-sided at a significance of $\alpha=0.025$. Only if the previous null hypothesis could be rejected, the subsequent superiority test would be carried out in the following order: superiority of CIC $640 \mu \mathrm{g} \cdot$ day $^{-1}$ to FP $1,000 \mu \mathrm{g} \cdot$ day $^{-1}$ for difference in serum cortisol mesor; superiority of CIC $640 \mu \mathrm{g} \cdot \mathrm{day}^{-1}$ to FP $1,000 \mu \mathrm{g} \cdot \mathrm{day}^{-1}$ for change in 24-h urine cortisol adjusted for creatinine; superiority of CIC $320 \mu \mathrm{g} \cdot \mathrm{day}^{-1}$ to FP $500 \mu \mathrm{g} \cdot \mathrm{day}^{-1}$ for difference in serum cortisol mesor; superiority of CIC $320 \mu \mathrm{g} \cdot \mathrm{day}^{-1}$ to FP $1,000 \mu \mathrm{g} \cdot \mathrm{day}^{-1}$ for change in $24-\mathrm{h}$ urine cortisol adjusted for creatinine.

All statistical analyses were carried out with SAS (release 9.1; SAS Institute Inc., Cary, NC, USA). Serum cortisol mesor, urine cortisol variables, bone formation markers, log-transformed PC20 and lung variables were analysed by means of an ANCOVA or ANOVA [26] with treatment, period, sequence, patient within sequence and sex as factors. For computation of the ANOVA and ANCOVA analyses the SAS procedure PROC MIXED was utilised, using the baseline value as continuous covariate, the patient within sequence effect as random nested factor and all other factors as fixed effects. Asthma pretreatment and centre as factors were added for specific endpoints or analyses. T-tests of difference between the treatment least square means are given as two-sided, with an $\alpha$-level of $5 \%$. The sample size was estimated based on findings from a previous study [14]. In the case of normally distributed difference in time-averaged cortisol levels AUC0-24h, a sample size of 30 randomised patients was estimated to ensure a power of $80 \%$ to correctly conclude a difference in mean values
TABLE 2 Baseline demographics and characteristics

\begin{tabular}{|c|c|}
\hline Subjects & 32 \\
\hline Age yrs & $27(18-59)$ \\
\hline Weight kg & $70 \pm 16$ \\
\hline Height $\mathrm{cm}$ & $171 \pm 9$ \\
\hline \multicolumn{2}{|l|}{ Sex } \\
\hline Male & 12 \\
\hline Female & 20 \\
\hline \multicolumn{2}{|l|}{ Race } \\
\hline Caucasian & 31 \\
\hline Black & 1 \\
\hline \multicolumn{2}{|l|}{ ICS pre-treatment } \\
\hline ICS & 12 \\
\hline ICS/LABA & 20 \\
\hline \multicolumn{2}{|l|}{ Smoking status } \\
\hline Nonsmokers & 19 \\
\hline Ex-smokers & 11 \\
\hline Current smokers & 2 \\
\hline FEV $_{1} \%$ predicted $^{\#}$ & $84.9 \pm 13.2$ \\
\hline Mean $\mathrm{PC}_{20}$ AMP $\mathrm{mg} \cdot \mathrm{mL}^{-1}$ & $16.7(2.0-60)$ \\
\hline Mean $\mathrm{PC}_{20} \mathrm{MCh} \mathrm{mg} \cdot \mathrm{mL}^{-1}$ & $2.0(0.1-8.0)$ \\
\hline
\end{tabular}

Data are presented as $n$, median (range) or mean \pm SD. ICS: inhaled corticosteroid; LABA: long-acting $\beta_{2}$-agonist; FEV 1 : forced expiratory volume in $1 \mathrm{~s}$; PC20: provocative concentration leading to a $20 \%$ decrease in FEV 1 ; AMP: adenosine 5-monophosphate; MCh: methacholine. ${ }^{*}$ : taken at randomisation.

of $49 \mathrm{nmol} \cdot \mathrm{L}^{-1}$ under assumption of a common SD of $66.6 \mathrm{nmol} \cdot \mathrm{L}^{-1}$. The sample size estimation was based on a two-independent group t-test which provides a conservative acceptable approximation of the t-test for comparing leastsquare means utilised in the PROC MIXED procedure.

\section{RESULTS}

\section{Patient characteristics}

A total of 83 patients were screened. Of these, 51 were not eligible because of a negative methacholine or negative adenosine challenge test. The remaining 32 patients (20 females) were randomised (table 2, fig. 2). The first patient was included on May 27, 2003, and the last patient left the study on April 10, 2006. The characteristics of the 32 patients included in the study are summarised in table 2. Median age was 27 yrs. Most patients were pre-treated with a combination of a LABA and an ICS. Mean PC20 methacholine was $2.0 \mathrm{mg} \cdot \mathrm{mL}^{-1}$ and mean PC20 adenosine was $16.7 \mathrm{mg} \cdot \mathrm{mL}^{-1}$. Washout period was 4 weeks on most occasions, and did not exceed 8 weeks. There were no dropouts due to asthma exacerbations. Two patients ended the study prematurely for nonmedical reasons and were excluded from the safety analysis. One further patient was excluded from all analysis for erroneously using his previous ICS (FP Diskus; GlaxoSmithKline, Ware, UK) during the study.

\section{Cortisol assessments}

\section{Serum cortisol mesor}

The serum cortisol mesor data are presented in table 3. Both FP doses significantly suppressed cortisol secretion versus placebo, serum cortisol reaching $323.0 \pm 22.6 \mathrm{nmol} \cdot \mathrm{L}^{-1}$ after 


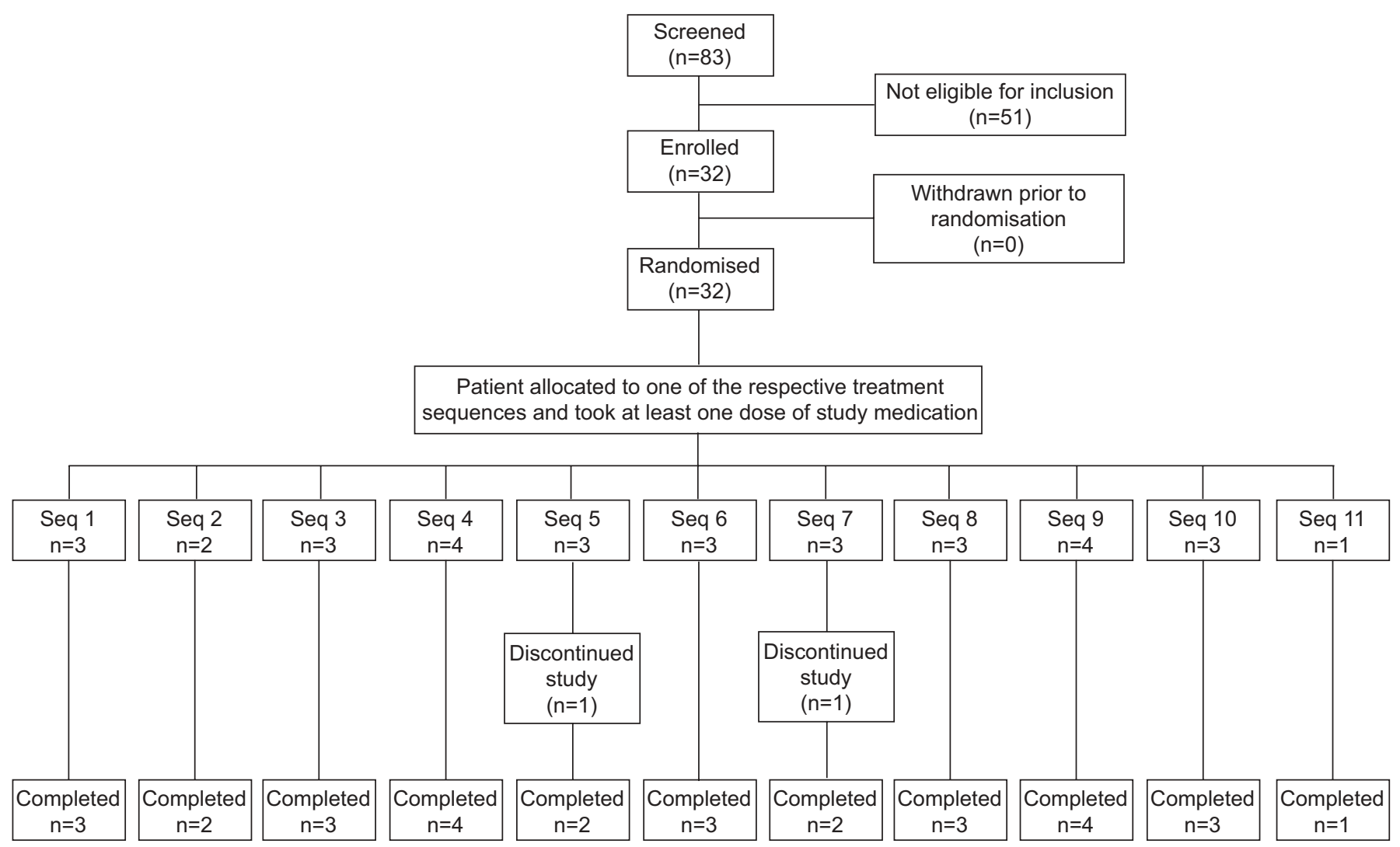

FIGURE 2. Consort diagram showing the flow of the patients. In total, 83 patients were screened and 32 patients received study medication according to one of 10 sequences (seq). Two patients discontinued the study for nonmedical reasons. The sequence of the patient who erroneously continued to use his FP Diskus (GlaxoSmithKline, Ware, UK) on top of his study medication, was a posteriori called sequence 11, since that treatment did not correspond with one of 10 sequences originally scheduled before the start of the study

FP $500 \mu \mathrm{g} \cdot \mathrm{day}^{-1}(-46.2(95 \%$ confidence interval (CI) $-83.8-18.5)$ $\mathrm{nmol} \cdot \mathrm{L}^{-1}$ or $\left.-10.3 \%\right)$ and $293.0 \pm 22.3 \mathrm{nmol} \cdot \mathrm{L}^{-1}$ after $\mathrm{FP}$ $1,000 \mu \mathrm{g} \cdot$ day $^{-1} \quad\left(-76.1 \quad(95 \%\right.$ CI $\quad-112.9--39.3) \quad \mathrm{nmol} \cdot \mathrm{L}^{-1}$ or $-19.8 \%)$. Differences in supression between FP $1,000 \mu \mathrm{g} \cdot \mathrm{day}^{-1}$ and the CIC $320 \mu \mathrm{g} \cdot \mathrm{day}^{-1}\left(-48.0(95 \% \mathrm{CI}-11.1--84.8) \mathrm{nmol} \cdot \mathrm{L}^{-1}\right)$ and CIC $640 \mu \mathrm{g} \cdot$ day $^{-1}\left(-38.8(95 \%\right.$ CI $\left.-1.9-175.7) \mathrm{nmol} \cdot \mathrm{L}^{-1}\right)$ treatments also reached statistical significance. Neither dose of CIC had a significant suppressive effect (table 3, fig. 3).

\section{4-h urine cortisol adjusted for creatinine}

Data for 24-h urine cortisol adjusted for creatinine are presented in table 3. Urinary cortisol excretion over $24 \mathrm{~h}$ adjusted for creatinine was significantly suppressed by both FP doses as compared with placebo. Neither dose of CIC demonstrated a significant effect on 24-h urinary cortisol adjusted for creatinine compared with placebo.

\section{Assessments of bone formation markers}

No significant differences were noted after either CIC treatment compared with placebo for any bone formation marker assessed (table 4). However, FP 1,000 $\mu \mathrm{g} \cdot \mathrm{day}^{-1}$ caused significant decreases in P1NP $(p=0.0126)$ and serum osteocalcin levels $(\mathrm{p}=0.0054)$ compared with placebo (table 4$)$.

\section{Pulmonary function measures}

FEV1 remained stable over time, with $90 \mathrm{~mL}$ being the largest difference between the highest and the lowest value. Changes from baseline in $\mathrm{FEV} 1 \%$ pred (least square means) were small for all treatments (CIC $320 \mu \mathrm{g} \cdot \mathrm{day}^{-1}$ : $-0.2 \%$; CIC $640 \mu \mathrm{g} \cdot \mathrm{day}^{-1}$ : $-0.3 \%$; FP $500 \mu \mathrm{g} \cdot$ day $^{-1}$ : $1.4 \%$; FP $1,000 \mu \mathrm{g} \cdot$ day $^{-1}$ : $3.3 \%$; placebo: $-3.1 \%$ ).

Methacholine and adenosine 5-monophosphate challenge Mean PC20 methacholine, which was $2.0 \mathrm{mg} \cdot \mathrm{mL}^{-1}$ at inclusion increased during the study by one doubling concentration (DC), reaching $5.6 \mathrm{mg} \cdot \mathrm{mL}^{-1}$ under placebo conditions. In this case, placebo means that patients remained under an evening dose of CIC $160 \mu \mathrm{g}$ throughout the study. Further improvements in airway hyperresponsiveness with the active treatments were small compared with placebo and were less than one DC (fig. 4, table 5). Thus, PC20 methacholine after the two FP treatments increased by 0.6 and 0.7 DC compared with placebo $(p \leqslant 0.0228)$, whereas the changes in hyperresponsiveness ( 0.3 and 0.5 DC) after CIC did not reach statistical significance (table 5). Statistically significant differences between the CIC and FP treatments for PC20 methacholine challenge were not observed.

Mean PC20 adenosine, which was $16.7 \mathrm{mg} \cdot \mathrm{mL}^{-1}$ at inclusion, increased during the study by almost two DC, reaching $51.3 \mathrm{mg} \cdot \mathrm{mL}^{-1}$ under placebo conditions. The further increase in PC20 adenosine with all four treatments was statistically significant compared with placebo, ranging between one and two DC ( $p<0.05$; fig. 5, table 5). Differences between the lower and the higher dose of CIC did not reach statistical 
TABLE 3 Effects of treatments on serum cortisol mesor and urine cortisol, adjusted for creatinine

\begin{tabular}{|c|c|c|c|c|c|}
\hline & Placebo $^{\#}$ & CIC $320 \mu \mathrm{g} \cdot$ day $^{-1}$ & CIC $640 \mu \mathrm{g} \cdot$ day $^{-1}$ & FP $500 \mu \mathrm{g} \cdot \mathrm{day}^{-1}$ & FP $1000 \mu \mathrm{g} \cdot$ day $^{-1}$ \\
\hline \multicolumn{6}{|l|}{ Serum cortisol mesor $\mathrm{nmol} \cdot \mathrm{L}^{-1}$} \\
\hline Mean \pm SD & $381.2 \pm 98.5$ & $352.8 \pm 110.4$ & $341.6 \pm 95.9$ & $332.9 \pm 94.2$ & $304.4 \pm 150.6$ \\
\hline LS mean \pm SEM & $369.2 \pm 22.6$ & $341.0 \pm 22.7$ & $331.8 \pm 22.7$ & $323.0 \pm 22.6$ & $293.0 \pm 22.3$ \\
\hline \multicolumn{6}{|l|}{ Difference versus placebo } \\
\hline $\mathrm{p}$-value & & 0.0251 & 0.0687 & 0.0084 & $<0.0001$ \\
\hline \multicolumn{6}{|l|}{ Difference versus FP $1000 \mu \mathrm{g} \cdot$ day $^{-1}$} \\
\hline LS mean \pm SEM & $76.1 \pm 18.6$ & $48.0 \pm 18.6$ & $38.8 \pm 18.6$ & $30.0 \pm 18.7$ & \\
\hline $95 \% \mathrm{Cl}$ & $39.3-112.9$ & $11.1-84.8$ & $1.9-75.7$ & $-7.2-67.1$ & \\
\hline$p$-value & 0.0001 & 0.0057 & 0.0197 & 0.0563 & \\
\hline Subjects $n$ & 25 & 26 & 27 & 27 & 28 \\
\hline Mean $\pm S D$ & $25.74 \pm 17.24$ & $22.95 \pm 10.17$ & $23.72 \pm 10.75$ & $20.49 \pm 7.49$ & $20.74 \pm 10.93$ \\
\hline LS mean \pm SEM after treatment & $25.04 \pm 2.44$ & $22.12 \pm 2.43$ & $23.32 \pm 2.39$ & $20.06 \pm 2.39$ & $19.80 \pm 2.37$ \\
\hline Difference versus placebo LS mean \pm SEM & & $-2.92 \pm 2.38$ & $-1.72 \pm 2.35$ & $-4.98 \pm 2.36$ & $-5.24 \pm 2.32$ \\
\hline $95 \% \mathrm{Cl}$ & & $-7.64-1.80$ & $-6.38-2.94$ & $-9.66--0.30$ & $-9.84--0.64$ \\
\hline p-value & & 0.1111 & 0.2326 & 0.0186 & 0.0130 \\
\hline
\end{tabular}

For all safety parameters: the data provided are for the restricted safety analysis, excluding one patient. CIC: ciclesonide; FP: fluticasone propionate; LS: least squares; Cl: confidence interval. ${ }^{*}$ : maintenance dose of CIC $160 \mu \mathrm{g} \cdot$ day $^{-1}$.

significance. Likewise, the differences between the two FP doses were not statistically significant. FP $500 \mu \mathrm{g} \cdot$ day $^{-1}$ resulted in significantly greater improvements in PC20 adenosine (one DC) compared with CIC $320 \mu \mathrm{g} \cdot \mathrm{day}^{-1}(\mathrm{p}=0.0238)$. No

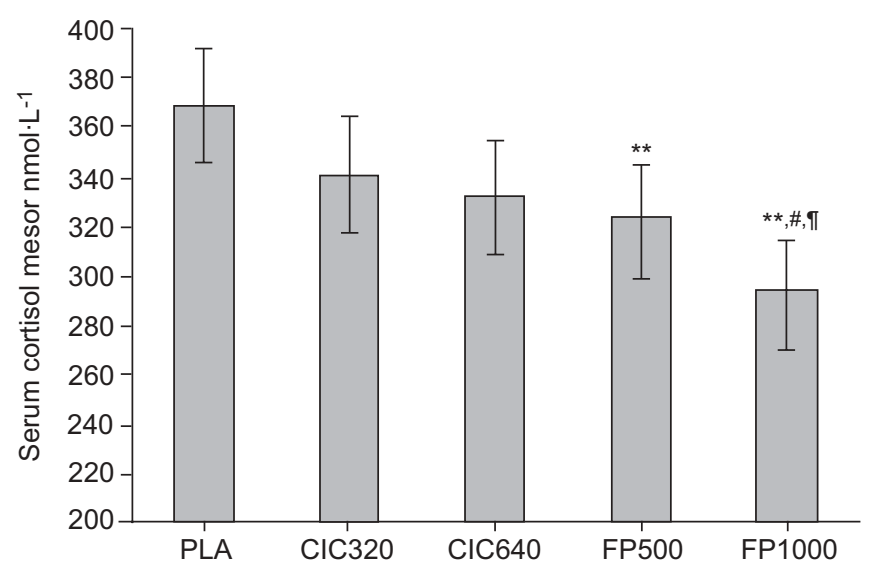

FIGURE 3. Mean serum cortisol mesor following placebo (PLA), ciclesonide (CIC) $320 \mu \mathrm{g} \cdot \mathrm{day}^{-1}$ (CIC320), ClC $640 \mu \mathrm{g} \cdot \mathrm{day}^{-1}$ (CIC640), fluticasone propionate (FP) $500 \mu \mathrm{g} \cdot \mathrm{day}^{-1}$ (FP500) or FP 1,000 $\mu \mathrm{g} \cdot \mathrm{day}^{-1}$ (FP1000). All treatment groups were administered $\mathrm{CIC} 160 \mu \mathrm{g}$ once daily in the evening plus salmeterol $50 \mu \mathrm{g}$ twice daily. Data are presented as at least squares mean $\pm S D .{ }^{*}: p<0.01$ versus PLA; ${ }^{*}: \mathrm{p} \leqslant 0.0057$ versus CIC $320 \mu \mathrm{g} \cdot \mathrm{day}^{-1} ;{ }^{\circ}: \mathrm{p}=0.0197$ versus CIC $640 \mu \mathrm{g} \cdot \mathrm{day}^{-1}$. significant difference was seen between CIC $640 \mu \mathrm{g} \cdot \mathrm{day}^{-1}$ and FP $1,000 \mu \mathrm{g} \cdot$ day $^{-1}$, or between other doses.

In total, 22 patients experienced 56 AEs during the treatment period. The percentage of patients experiencing AEs was comparable across all treatment groups (CIC $320 \mu \mathrm{g} \cdot \mathrm{day}^{-1}$, $33.3 \%$; CIC $640 \mu \mathrm{g} \cdot$ day $^{-1}, 26.7 \%$; FP $500 \mu \mathrm{g} \cdot$ day $^{-1}, 31.3 \%$; FP $1,000 \mu \mathrm{g} \cdot \mathrm{day}^{-1}, 22.6 \%$; placebo, $\left.33.3 \%\right)$. The majority of AEs were mild or moderate in intensity and none was assessed as definitely related to study medication. One patient in the placebo group reported two serious AEs (face oedema and laryngeal oedema), which were caused by allergy to concomitant use of antibiotics and resolved completely.

\section{DISCUSSION}

The present study is the first placebo-controlled, crossover study assessing simultaneously the effects of ICS on cortisol secretion, bone markers and bronchial hyperresponsiveness in ICS-dependent asthma patients. The results indicate that daily doses of CIC $320 \mu \mathrm{g}$ and $640 \mu \mathrm{g}$, administered in addition to a low maintenance dose of CIC $160 \mu \mathrm{g} \cdot \mathrm{day}^{-1}$, did not appear to exert significant systemic effects, whereas daily doses of FP $500 \mu \mathrm{g}$ and 1,000 $\mu \mathrm{g}$ significantly suppressed adrenal function and bone formation markers. All active treatments improved airway responsiveness, but clinically relevant differences between the treatments were not observed.

The magnitude of the suppression of serum cortisol mesor, the primary variable, reached $10 \%$ with FP $500 \mu \mathrm{g} \cdot$ day $^{-1}$ and 
TABLE 4 Least squares (LS) mean changes in bone formation markers compared with placebo ${ }^{\#}$

\begin{tabular}{|c|c|c|c|c|}
\hline & CIC $320 \mu \mathrm{g} \cdot$ day $^{-1}$ & CIC $640 \mu \mathrm{g} \cdot$ day $^{-1}$ & FP $500 \mu \mathrm{g} \cdot$ day $^{-1}$ & FP $1000 \mu \mathrm{g} \cdot$ day $^{-1}$ \\
\hline Subjects $n$ & 27 & 27 & 27 & 27 \\
\hline LS mean \pm SEM & $-2.7 \pm 4.1$ & $0.8 \pm 4.1$ & $-3.3 \pm 4.2$ & $-10.4 \pm 4.1$ \\
\hline $95 \% \mathrm{Cl}$ & $-10.9-5.5$ & $-7.4-9.0$ & $-11.6-4.9$ & $-18.4--2.3$ \\
\hline $\mathrm{p}$-value & 0.5156 & 0.8376 & 0.4258 & 0.0126 \\
\hline $95 \% \mathrm{Cl}$ & $-1.7-3.0$ & $-2.4-2.3$ & $-4.2-0.6$ & $-5.6--1.0$ \\
\hline $\mathrm{p}$-value & 0.5814 & 0.9799 & 0.1312 & 0.0054 \\
\hline \multicolumn{5}{|c|}{ Bone specific AP $\mu \mathrm{g} \cdot \mathrm{L}^{-1}$} \\
\hline LS mean \pm SEM & $0.4 \pm 0.4$ & $-0.1 \pm 0.4$ & $0.3 \pm 0.4$ & $0.0 \pm 0.4$ \\
\hline $95 \% \mathrm{Cl}$ & $-0.4-1.2$ & $-0.9-0.7$ & $-0.5-1.1$ & $-0.7-0.8$ \\
\hline
\end{tabular}

CIC: ciclesonide; FP: fluticasone propionate; P1NP: N-terminal propetide of type 1 pro-collagen; Cl: confidence interval; AP: alkaline phosphatase. The p-values are set versus placebo. ${ }^{\#}$ : maintenance dose of $\mathrm{CIC} 160 \mu \mathrm{g} \cdot$ day $^{-1}$.

almost $20 \%$ with FP $1,000 \mu \mathrm{g} \cdot$ day $^{-1}$, administered in addition to a low maintenance dose of CIC $160 \mu \mathrm{g} \cdot$ day $^{-1}$. Likewise, 24-h urinary cortisol excretion (adjusted for creatinine) was lower with FP than with placebo treatment. Substantial suppression of adrenal function after inhalation of FP has been previously reported in healthy volunteers [19] and asthmatic patients [14, 20-22]. The presently observed degree of adrenal suppression with FP $1,000 \mu \mathrm{g} \cdot \mathrm{day}^{-1}$ is somewhat smaller than the $29-34 \%$ suppression reported previously [14, 17, 20], possibly because it was given on top of a low maintenance dose of inhaled CIC. The duration of the treatment cannot explain the difference between the currently and previously reported decreases in suppression, as adrenal suppression with inhaled FP is close to maximum after 7 days [27]. Possibly, the alterations in pulmonary function and airway inflammation in patients with

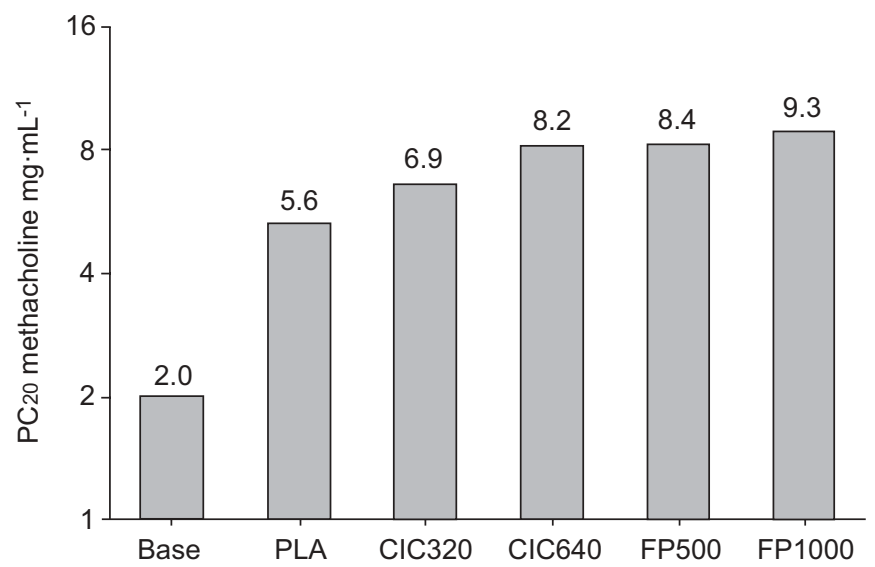

FIGURE 4. Provocative concentration leading to a $20 \%$ decrease in forced expiratory volume in $1 \mathrm{~s}$ (PC20) methacholine at intake (base) and after placebo (PLA), ciclesonide (CIC) and fluticasone propionate (FP). All treatment groups were administered $\mathrm{CIC} 160 \mu \mathrm{g}$ once daily in the evening plus salmeterol $50 \mu \mathrm{g}$ twice daily. CIC320: CIC $320 \mu \mathrm{g} \cdot$ day $^{-1}$; CIC640: CIC $640 \mu \mathrm{g} \cdot$ day $^{-1}$; FP500: $500 \mu \mathrm{g} \cdot$ day $^{-1}$; FP1000: FP 1,000 $\mu \mathrm{g} \cdot \mathrm{day}^{-1}$. more severe asthma resulted in a less distal lung deposition of $\mathrm{FP}$, leading to a reduced pulmonary absorption, a decreased systemic bioavailability and a less pronounced adrenal suppression [22, 28-30].

In contrast to FP, CIC $320 \mu \mathrm{g} \cdot \mathrm{day}^{-1}$ and $640 \mu \mathrm{g} \cdot \mathrm{day}^{-1}$, even when administered in addition to a low maintenance dose of CIC $160 \mu \mathrm{g} \cdot \mathrm{day}^{-1}$, did not significantly alter cortisol production. Indeed, mean change in serum cortisol was $-6.1 \%$ for CIC $320 \mu \mathrm{g} \cdot \mathrm{day}^{-1}$ and $-7.9 \%$ for CIC $640 \mu \mathrm{g} \cdot \mathrm{day}^{-1}$, which is in complete agreement with changes reported in previous studies $[14,17]$. An important finding was that differences in serum cortisol mesor between FP $1,000 \mu \mathrm{g} \cdot \mathrm{day}^{-1}$ and the two CIC treatments reached statistical significance. Similar observations have been reported in other studies, in which the systemic effects of CIC and FP in healthy volunteers or patients with mild asthma have been assessed [14-17], albeit at higher doses. Thus, it appears that the effects on the 24-h cortisol profile induced by FP are an intrinsic characteristic of this molecule and occur in both healthy subjects and patients with intermittent and persistent asthma. Interestingly, such effects have not been reported with CIC, even in doses as high as $1,280 \mu \mathrm{g} \cdot$ day $^{-1}[14,17]$.

Differences in pharmacokinetic properties between FP and CIC may largely explain the more beneficial profile of CIC [31, 32]. Although the clinical relevance and long-term consequences of mild adrenal suppression remain to be elucidated, the potential clinical relevance of this finding should not be underestimated. Moreover, the wide confidence intervals for serum cortisol for all comparisons indicate that the individual variability of the response of the HPA-axis and the potential occurrence of measurable systemic effects towards different doses of different inhaled steroids cannot be neglected. Indeed, a substantial number of patients with moderate or severe asthma are treated with high doses of FP, i.e. $\geqslant 1,000 \mu \mathrm{g} \cdot \mathrm{day}^{-1}$, in order to reach asthma control $[5,33]$.

Admittedly, a carry-over effect could have been missed since this study was powered for the primary outcome. However, it 


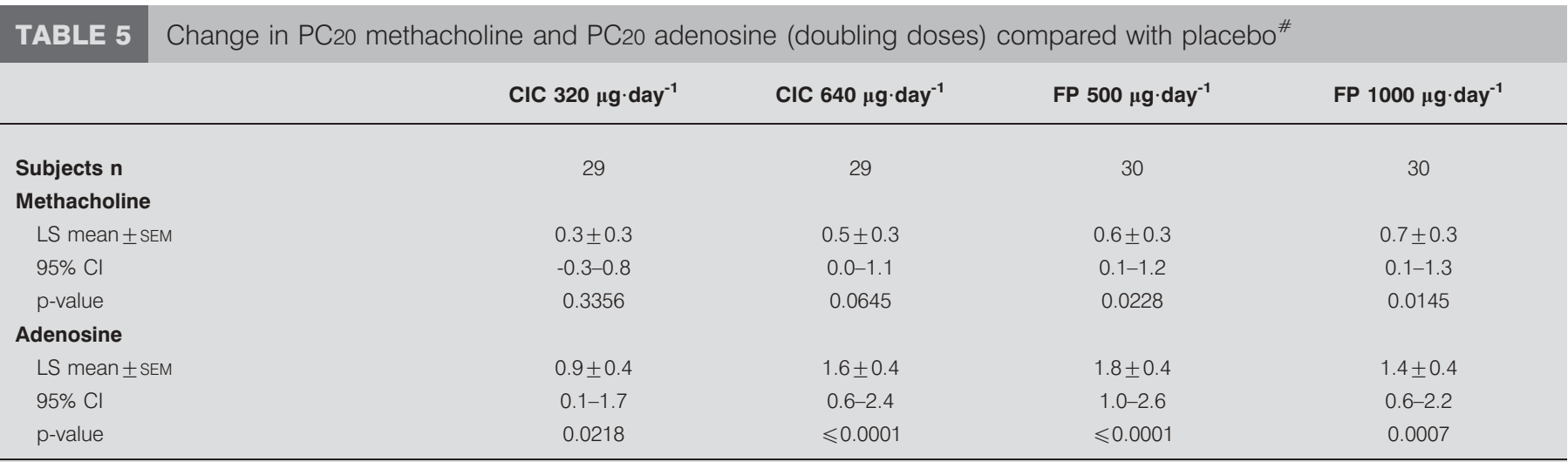

PC20: provocative concentration leading to a $20 \%$ decrease in forced expiratory volume in 1 s; CIC: ciclesonide; FP: fluticasone propionate; LS: least squares; $\mathrm{Cl}$ : confidence interval. ${ }^{*}$ : maintenance dose of CIC $160 \mu \mathrm{g} \cdot$ day $^{-1}$

is unlikely that such a carry-over effect may have occurred, since des-ciclesonide has a half-life of just over $3 \mathrm{~h}$ [32] and fluticasone has a half-life of 7-14 h [31], whereas washout in the present study was at least 4 weeks. Moreover, cortisol secretion recovers completely $24 \mathrm{~h}$ after a single inhalation of $1,000 \mu \mathrm{g}$ fluticasone [24], while PC20 adenosine normalises completely 4 weeks after discontinuation of treatment with inhaled steroids [14, 34].

Looking at markers of bone metabolism is a different way of assessing systemic effects of ICS. The current study suggests that FP 1,000 $\mu \mathrm{g} \cdot$ day $^{-1}$ significantly decreased P1NP and serum osteocalcin, whereas the lower dose of FP and both doses of ICS did not. Long-term studies with FP, in which doses of 400$750 \mu \mathrm{g} \cdot$ day $^{-1}$ were administered for $1-2$ yrs, demonstrated no clinically relevant effect on markers of bone formation compared with baseline $[35,36]$. To the best of our knowledge, no studies with higher doses of FP have been performed to date. The clinical relevance of our findings remains to be

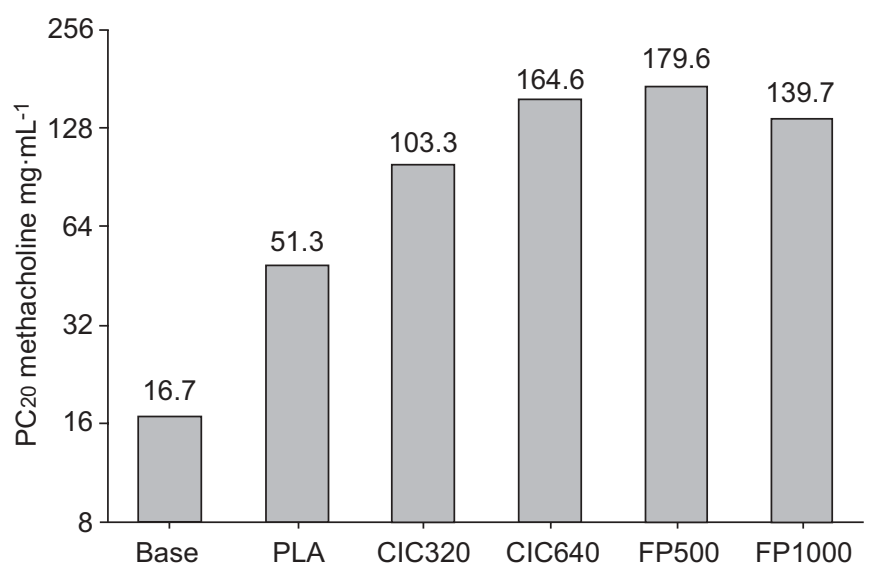

FIGURE 5. Provocative concentration leading to a $20 \%$ decrease in forced expiratory volume in $1 \mathrm{~s}$ (PC20) adenosine at intake (base) and after placebo (PLA), ciclesonide $(\mathrm{CIC})$ and fluticasone (FP). All treatment groups were administered $\mathrm{CIC}$ $160 \mu \mathrm{g}$ once daily in the evening plus salmeterol $50 \mu \mathrm{g}$ twice daily. CIC320: CIC $320 \mu \mathrm{g} \cdot \mathrm{day}^{-1}$; CIC640: CIC $640 \mu \mathrm{g} \cdot \mathrm{day}^{-1}$; FP500: $500 \mu \mathrm{g} \cdot \mathrm{day}^{-1}$; FP1000: FP $1,000 \mu \mathrm{g} \cdot \mathrm{day}^{-1}$. determined, although some evidence exists that long-term ICS use affects bone mineral density and increases the risk of fractures [6].

The secondary end-points of the present study compared the clinical effects of the different treatments with those seen with placebo. Although FEV1 is often used as a marker for the clinical effect of anti-asthma drugs, this test cannot be used to establish the relative potency of ICS [14, 20]. This is confirmed in the present trial as the observed differences in FEV1 between active and placebo treatments were very small. However, it has been suggested that challenges tests with methacholine [37] and adenosine [38] might be more appropriate to differentiate the effects of high and low doses of ICS. In previous studies, $\mathrm{CIC}$, inhaled via a dry powder inhaler, has demonstrated dosedependent improvements in adenosine challenge up to doses of $1,280 \mu \mathrm{g} \cdot$ day $^{-1}[14,38]$, and significant protective effects versus placebo at doses as low as $160 \mu \mathrm{g} \cdot \mathrm{day}^{-1}$ may be expected [12]. Likewise, dose-dependent protective effects of FP against adenosine and methacholine challenge have been documented in previous studies [39].

With regard to the current study, the overall effects of the ICS on bronchial hyperresponsiveness against methacholine were small, with the observed changes ranging between 0.3 and 0.7 DC. This is in keeping with previously published data [15, 23, 39]. In the present study, in which FP and CIC were inhaled on top of a low maintenance dose of $\mathrm{CIC}$, only the improvement by 0.6 and $0.7 \mathrm{DC}$ with the two doses of FP reached statistical significance, a finding of little clinical relevance. These small increases did not allow us to establish the relative potency of the four treatments. Possibly, greater and more discriminative effects could have been obtained by prolonging each treatment to 52 weeks, a time-point at which the maximum effects of ICS on PC20 methacholine may be expected [40].

Adenosine-induced bronchoconstriction has been shown to be a sensitive marker of airway inflammation by promoting the release of a variety of inflammatory mediators [41], correlating with both exhaled nitric oxide and sputum, blood and bronchial tissue eosinophilia [42] and appears to be better suited to assess the anti-inflammatory effects of ICS than methacholine [43, 44]. In the present study, the room for 
improvement in PC20 with both CIC and FP was larger with adenosine than with methacholine, a finding that is in line with a study in which a high dose of ICS increased PC20 adenosine by 3.1 DC and PC20 methacholine by only 1.5 DC [43]. Nevertheless, the absolute increases in PC20 adenosine with FP and CIC observed in the present study did not exceed two DC, when compared with placebo. This contrasts with previous data by PHILLIPS et al. [45] for FP and by TAYLOR et al. [38] and KANNIESS et al. [46] for CIC. Thus, CIC $400 \mu \mathrm{g} \cdot$ day $^{-1}$ administered via a dry powder inhaler for 14 days increased PC20 adenosine by 2.0 DC and 2.4 DC according to TAYLOR et al. [38] and KANNIESS et al. [46], respectively, and 1,600 $\mu \mathrm{g} \cdot$ day $^{-1}$ increased PC20 adenosine by 3.4 DC $[38,46]$. In a study with FP $1,000 \mu \mathrm{g} \cdot$ day $^{-1}$, PC20 adenosine increased by $\sim 4.5$ DC [45].

Differences in methodology may largely explain the observed between-study differences in magnitude of effect. Firstly, the maximum treatment period of 10-12 days, chosen to avoid an overall study duration in excess of 6 months, may have limited the increase in PC20 adenosine, which requires up to 4 weeks to reach a maximum $[37,45,47]$. Moreover, the administration of a maintenance dose of CIC $160 \mu \mathrm{g} \cdot$ day $^{-1}$ to preserve asthma control may have contributed to the unexpected, more than two-fold increase in PC20 adenosine, compared with PC20 values obtained at inclusion. Possibly, inclusion into the study improved adherence to treatment, which in daily life is known to be less than optimal in many asthma patients. This unexpected rise in DC limited room for further improvements in PC20 adenosine with any of the active treatments. As the overall improvements in bronchoprotection against adenosine were small (only the difference between CIC $320 \mu \mathrm{g} \cdot$ day $^{-1}$ and FP $500 \mu \mathrm{g} \cdot \mathrm{day}^{-1}$ reached statistical significance), the relative potencies of the different treatments could not be established.

In summary, results from the current study indicate that fluticasone propionate $500 \mu \mathrm{g} \cdot \mathrm{day}^{-1}$ and $1,000 \mu \mathrm{g} \cdot \mathrm{day}^{-1}$ exerted systemic effects in patients with moderate persistent asthma, whereas ciclesonide $320 \mu \mathrm{g} \cdot \mathrm{day}^{-1}$ or $640 \mu \mathrm{g} \cdot \mathrm{day}^{-1} \mathrm{did}$ not affect either biochemical markers of bone formation or serum and urinary cortisol values, if administered in addition to a low ciclesonide dose. Although the long-term clinical meaning of these markers remains to be investigated, they do suggest that ciclesonide yields less systemic effects than fluticasone propionate in patients with moderate persistent asthma for a similar protective activity. The importance of this issue cannot be overestimated in the light of the currently accepted aims of asthma treatment [5], in which disease control with higher doses of inhaled corticosteroid features is the primary objective.

\section{ACKNOWLEDGEMENTS}

It is a pleasure to acknowledge the late R. Pauwels (Dept of Respiratory Medicine, Ghent University Hospital, Ghent, Belgium) for his contribution to the design of the study, J. Dunkel (Nycomed Pharma, Konstanz, Germany) for statistical advice, and V. Collart (Dept of Respiratory Medicine, Ghent University Hospital), J. Sele (Dept of Respiratory Diseases, University de Liege, Liege, Belgium), G. Van Severen and S. Verschraegen (both Dept of Respiratory Medicine, Ghent University Hospital) for excellent technical assistance. The authors would also like to thank A. Owen (Medicus International, London, UK) for his editorial assistance.

\section{REFERENCES}

1 Barnes PJ, Pedersen S, Busse WW. Efficacy and safety of inhaled corticosteroids. New developments. Am J Respir Crit Care Med 1998; 157: S1-S53.

2 Banov C, Howland WC III, Lumry WR, et al. Budesonide turbuhaler delivered once daily improves health-related quality of life in adult patients with non-steroid-dependent asthma. Allergy Asthma Proc 2003; 24: 129-136.

3 Suissa S, Ernst P, Kezouh A. Regular use of inhaled corticosteroids and the long term prevention of hospitalisation for asthma. Thorax 2002; 57: 880-884.

4 Suissa S, Ernst P, Benayoun S, et al. Low-dose inhaled corticosteroids and the prevention of death from asthma. $N$ Engl J Med 2000; 343: 332-336.

5 Global Initiative for Asthma (GINA) Executive Committee. Global Strategy for Asthma Management and Prevention. GINA 2006. www.ginasthma.com Date last accessed: April 3, 2009. Date last updated: December 2008.

6 Kelly HW. Potential adverse effects of the inhaled corticosteroids. J Allergy Clin Immunol 2003; 112: 469-478.

7 Todd GR, Acerini CL, Ross-Russell R, et al. Survey of adrenal crisis associated with inhaled corticosteroids in the United Kingdom. Arch Dis Child 2002; 87: 457-461.

8 Bender BG, Bender SE. Patient-identified barriers to asthma treatment adherence: responses to interviews, focus groups, and questionnaires. Immunol Allergy Clin North Am 2005; 25: 107-130.

9 Adams RJ, Fuhlbrigge A, Guilbert T, et al. Inadequate use of asthma medication in the United States: results of the asthma in America national population survey. J Allergy Clin Immunol 2002; 110: 58-64.

10 Mutch E, Nave R, McCracken N, et al. The role of esterases in the metabolism of ciclesonide to desisobutyryl-ciclesonide in human tissue. Biochem Pharmacol 2007; 73: 1657-1664.

11 Pearlman DS, Berger WE, Kerwin E, et al. Once-daily ciclesonide improves lung function and is well tolerated by patients with mild-to-moderate persistent asthma. J Allergy Clin Immunol 2005; 116: 1206-1212.

12 Wilson AM, Duong M, Pratt B, et al. Anti-inflammatory effects of once daily low dose inhaled ciclesonide in mild to moderate asthmatic patients. Allergy 2006; 61: 537-542.

13 Langdon CG, Adler M, Mehra S, et al. Once-daily ciclesonide 80 or 320 microg for 12 weeks is safe and effective in patients with persistent asthma. Respir Med 2005; 99: 1275-1285.

14 Derom E, Van De Velde V, Marissens S, et al. Effects of inhaled ciclesonide and fluticasone propionate on cortisol secretion and airway responsiveness to adenosine 5' monophosphate in asthmatic patients. Pulm Pharmacol Ther 2005; 18: 328-336.

15 Lee DK, Fardon TC, Bates CE, et al. Airway and systemic effects of hydrofluoroalkane formulations of high-dose ciclesonide and fluticasone in moderate persistent asthma. Chest 2005; 127: 851-860.

16 Lipworth BJ, Kaliner MA, La Force CF, et al. Effect of ciclesonide and fluticasone on hypothalamic-pituitary-adrenal axis function in adults with mild-to-moderate persistent asthma. Ann Allergy Asthma Immunol 2005; 94: 465-472.

17 Szefler S, Rohatagi S, Williams J, et al. Ciclesonide, a novel inhaled steroid, does not affect hypothalamic-pituitaryadrenal axis function in patients with moderate-to-severe persistent asthma. Chest 2005; 128: 1104-1114. 
18 Weinbrenner A, Huneke D, Zschiesche M, et al. Circadian rhythm of serum cortisol after repeated inhalation of the new topical steroid ciclesonide. J Clin Endocrinol Metab 2002; 87: 2160-2163.

19 Lönnebo A, Grahnén A, Jansson B, et al. An assessment of the systemic effects of single and repeated doses of inhaled fluticasone propionate and inhaled budesonide in healthy volunteers. Eur J Clin Pharmacol 1996; 49: 459-463.

20 Derom E, Van Schoor J, Verhaeghe W, et al. Systemic effects of inhaled fluticasone propionate and budesonide in adult patients with asthma. Am J Respir Crit Care Med 1999; 160: 157-161.

21 Clark DJ, Lipworth BJ. Adrenal suppression with chronic dosing of fluticasone propionate compared with budesonide in adult asthmatic patients. Thorax 1997; 52: 55-58.

22 Edsbäcker S, Wollmer P, Selroos O, et al. Do airway clearance mechanisms influence the local and systemic effects of inhaled corticosteroids? Pulm Pharmacol Ther 2007; 21: 247-258.

23 Lee DK, Haggart K, Currie GP, et al. Effects of hydrofluoroalkane formulations of ciclesonide 400 microg once daily vs fluticasone 250 microg twice daily on methacholine hyper-responsiveness in mild-to-moderate persistent asthma. Br J Clin Pharmacol 2004; 58: 26-33.

24 Thorsson L, Dahlstrom K, Edsbäcker S, et al. Pharmacokinetics and systemic effects of inhaled fluticasone propionate in healthy subjects. Br J Clin Pharmacol 1997; 43: 155-161.

25 Cockcroft DW, Killian DN, Mellon JJ, et al. Bronchial reactivity to inhaled histamine: a method and clinical survey. Clin Allergy 1977; 7: 235-243.

26 Gallo PP. Center-weighting issues in multicenter clinical trials. J Biopharm Stat 2000; 10: 145-163.

27 Whelan GJ, Blumer JL, Martin RJ, et al. Fluticasone propionate plasma concentration and systemic effect: effect of delivery device and duration of administration. J Allergy Clin Immunol 2005; 116: 525-530.

28 Brutsche $\mathrm{MH}$, Brutsche IC, Munawar M, et al. Comparison of pharmacokinetics and systemic effects of inhaled fluticasone propionate in patients with asthma and healthy volunteers: a randomised crossover study. Lancet 2000; 356: 556-561.

29 Harrison TW, Tattersfield AE. Plasma concentrations of fluticasone propionate and budesonide following inhalation from dry powder inhalers by healthy and asthmatic subjects. Thorax 2003; 58: 258-260.

30 Weiner P, Berar-Yanay N, Davidovich A, et al. Nocturnal cortisol secretion in asthmatic patients after inhalation of fluticasone propionate. Chest 1999; 116: 931-934.

31 Derendorf $\mathrm{H}$, Nave R, Drollmann A, et al. Relevance of pharmacokinetics and pharmacodynamics of inhaled corticosteroids to asthma. Eur Respir J 2006; 28: 1042-1050.

32 Derendorf $H$. Pharmacokinetic and pharmacodynamic properties of inhaled ciclesonide. J Clin Pharmacol 2007; 47: 782-789.

33 Bateman ED, Boushey HA, Bousquet J, et al. Can guidelinedefined asthma control be achieved? The Gaining Optimal Asthma ControL study. Am J Respir Crit Care Med 2004; 170: $836-844$.
34 Prosperini G, Rajakulasingam K, Cacciola RR, et al. Changes in sputum counts and airway hyperresponsiveness after budesonide: monitoring anti-inflammatory response on the basis of surrogate markers of airway inflammation. J Allergy Clin Immunol 2002; 110: 855-861.

35 Medici TC, Grebski E, Hacki M, et al. Effect of one year treatment with inhaled fluticasone propionate or beclomethasone dipropionate on bone density and bone metabolism: a randomised parallel group study in adult asthmatic subjects. Thorax 2000; 55: 375-382.

36 Li JT, Ford LB, Chervinsky P, et al. Fluticasone propionate powder and lack of clinically significant effects on hypothalamic-pituitary-adrenal axis and bone mineral density over 2 years in adults with mild asthma. J Allergy Clin Immunol 1999; 103: 1062-1068.

37 Kraan J, Koëter GH, van der Mark TW, et al. Dosage and time effects of inhaled budesonide on bronchial hyperreactivity. Am Rev Respir Dis 1988; 137: 44-48.

38 Taylor DA, Jensen MW, Kanabar V, et al. A dosedependent effect of the novel inhaled corticosteroid ciclesonide on airway responsiveness to adenosine-5'monophosphate in asthmatic patients. Am J Respir Crit Care Med 1999; 160: 237-243.

39 Nielsen LP, Dahl R. Therapeutic ratio of inhaled corticosteroids in adult asthma. A dose-range comparison between fluticasone propionate and budesonide, measuring their effect on bronchial hyperresponsiveness and adrenal cortex function. Am J Respir Crit Care Med 2000; 162: 2053-2057.

40 Ward C, Pais M, Bish R, et al. Airway inflammation, basement membrane thickening and bronchial hyperresponsiveness in asthma. Thorax 2002; 57: 309-316.

41 Peachell PT, Columbo M, Kagey-Sobotka A, et al. Adenosine potentiates mediator release from human lung mast cells. Am Rev Respir Dis 1988; 138: 1143-1151.

42 Polosa R, Li Gotti F, Mangano G, et al. Monitoring of seasonal variability in bronchial hyper-responsiveness and sputum cell counts in non-asthmatic subjects with rhinitis and effect of specific immunotherapy. Clin Exp Allergy 2003; 33: 873-881.

43 van den Berge $M$, Kerstjens HA, Meijer RJ, et al. Corticosteroid-induced improvement in the PC20 of adenosine monophosphate is more closely associated with reduction in airway inflammation than improvement in the PC20 of methacholine. Am J Respir Crit Care Med 2001; 164: 1127-1132.

44 Joos GF, O'Connor B, Anderson SD, et al. Indirect airway challenges. Eur Respir J 2003; 21: 1050-1068.

45 Phillips K, Oborne J, Lewis S, et al. Time course of action of two inhaled corticosteroids, fluticasone propionate and budesonide. Thorax 2004; 59: 26-30.

46 Kanniess F, Richter K, Böhme S, et al. Effect of inhaled ciclesonide on airway responsiveness to inhaled AMP, the composition of induced sputum and exhaled nitric oxide in patients with mild asthma. Pulm Pharmacol Ther 2001; 14: 141-147.

47 Currie GP, Fowler SJ, Lipworth BJ. Dose response of inhaled corticosteroids on bronchial hyperresponsiveness: a meta-analysis. Ann Allergy Asthma Immunol 2003; 90: 194-198. 